\title{
Diversity of algal viruses in various North American freshwater environments
}

\author{
Steven M. Short*, Cindy M. Short \\ Department of Biology, University of Toronto Mississauga, 3359 Mississauga Road North, Mississauga, \\ Ontario L5L 1C6, Canada
}

\begin{abstract}
To examine algal virus (Phycodnaviridae) genetic diversity in freshwater environments, gene fragments were cloned and sequenced from a river and a reservoir in Colorado, USA, and 2 different lakes in Ontario, Canada using PCR methods that target a diverse subset of known Phycodnaviridae DNA polymerase genes. Numerous phycodnavirus gene sequences were obtained from every sample, and rarefaction analysis of the sequence libraries demonstrated that virus richness was variable among different sample locations, and among samples collected from the same location at different times. Phylogenetic analysis of the unique sequences from each sample indicated that most sequences from the same geographic region (i.e. Colorado or Ontario) clustered together, but several exceptions were also observed. Phylogenetic analysis also demonstrated that the sequences obtained were more closely related to sequences from cultivated marine phycodnaviruses belonging to the genus Prasinovirus than to those from cultivated freshwater phycodnaviruses from the genus Chlorovirus. Overall, phycodnavirus sequences originating from cultivated marine viruses and marine clone libraries were not genetically distinct from the freshwater phycodnavirus sequences reported in this study.
\end{abstract}

KEY WORDS: Phycodnaviridae $\cdot$ Algal viruses $\cdot$ DNA polymerase $\cdot$ Diversity $\cdot$ Phylogeny

Resale or republication not permitted without written consent of the publisher

\section{INTRODUCTION}

Viruses are key components of aquatic ecosystems that affect material and energy flow through food webs and may influence species succession and community composition. Although viruses infecting freshwater Cyanobacteria were isolated as early as the 1960s (Safferman \& Morris 1963), aquatic ecologists paid little attention to these phytoplankton parasites until high abundances of viruses were reported in a variety of aquatic environments (Torrella \& Morita 1979, Bergh et al. 1989, Proctor \& Fuhrman 1990). Since then, ongoing work has consistently demonstrated that viruses are abundant, diverse, and active members of marine and freshwater ecosystems, and there are many excellent reviews of the aquatic virus literature (Fuhrman 1999, Wilhelm \& Suttle 1999, Wommack \& Colwell 2000, Brussaard 2004, Suttle 2005).
Early studies of virus-like particles in freshwater environments demonstrated that they were most abundant in eutrophic lakes (Bergh et al. 1989), were detectable in an ultra-oligotrophic lake (Klut \& Stockner 1990), and their abundance was positively related to chlorophyll a concentration, bacterial abundance, bacterial production, and lake trophic status (Maranger \& Bird 1995). Subsequent work has, for the most part, corroborated these findings and demonstrated that viruses are present in diverse freshwater environments including rivers (Farnell-Jackson \& Ward 2003), Antarctic lakes of varying salinity (Laybourn-Parry et al. 2001), meromictic lakes (Jacquet et al. 2005), an alkaline hypersaline lake (Jiang et al. 2004), oligotrophic lakes (Klut \& Stockner 1990, Vrede et al. 2003), mesotrophic lakes (Hennes \& Simon 1995, Wilhelm \& Smith 2000), and eutrophic lakes and reservoirs (Fischer \& Velimirov 2002, Weinbauer et al. 2003). Despite this growing body of knowledge of 
viruses in freshwater environments, most studies have focused on direct enumeration of virus-like particles or the influence of viruses on bacterioplankton mortality, and little is known about viruses that infect freshwater phytoplankton.

As noted above, the earliest reports of phytoplankton viruses arose from cultivation of viruses that infect freshwater Cyanobacteria (e.g., Safferman \& Morris 1963). The first reports of eukaryotic phytoplankton infection came from cultivation studies of viruses that parasitise the marine alga Micromonas pusilla (Mayer \& Taylor 1979) and freshwater symbiotic Chlorella-like algae (van Etten et al. 1982). Since then, the majority of viruses that infect eukaryotic algae (12 out of 13 virus genera) have been assigned to the virus family Phycodnaviridae, are classified as Nucleocytoplasmic Large DNA Viruses (NCLDVs) (Iyer et al. 2001), and have been cultivated from hosts belonging to the algal classes Chlorophyceae, Chrysophyceae, Dinophyceae, Phaeophyceae, Prasinophyceae, Prymnesiophyceae and Raphidophyceae (reviewed in: Brussaard 2004, Dunigan et al. 2006). Surprisingly, other than viruses that infect Chlorella-like algae, all viruses of eukaryotic phytoplankton have been cultivated from marine organisms. Reports of the genetic diversity of phycodnaviruses have focused on marine organisms and have included studies of the richness of cultivated and naturally occurring Coccolithovirus (Allen et al. 2007, Martinez et al. 2007) and Prasinovirus (Cottrell \& Suttle 1991, Zingone et al. 1999), and the richness of a diverse, but taxonomically undefined group of naturally-occurring phycodnavirus gene sequences (Short \& Suttle 2002, 2003). Thus, very little is known about the diversity of viruses that infect eukaryotic algae, especially those in freshwater environments.

Our purpose was to examine freshwater phycodnavirus gene sequences to provide the first survey of phycodnavirus diversity in freshwater environments, to determine whether viruses other than those that infect Chlorella-like algae can be recovered from freshwater environments, and to determine whether freshwater viruses are genetically distinct from marine viruses. To address questions about the richness and identity of freshwater viruses, algal virus gene fragments were amplified and sequenced from several distinct, geographically isolated, North American freshwater environments.

\section{MATERIALS AND METHODS}

Study sites and sample collection. Surface water samples were collected from 2 locations in Ontario, Canada and 2 in Colorado, USA using a bucket and 11 acid-rinsed HDPE bottles. The Ontario samples were collected from Crawford Lake (ca. 2.5 ha, $43^{\circ} 28.140^{\prime} \mathrm{N}, 79^{\circ} 56.954^{\prime} \mathrm{W}$, elevation $290 \mathrm{~m}$ ), a small meromictic lake located on the Niagara Escarpment about $70 \mathrm{~km}$ southwest of Toronto, and from a jetty in Mississauga on the Laurentian Great Lake, Lake Ontario (ca. $1.9 \times 10^{6}$ ha, $43^{\circ} 32.614^{\prime} \mathrm{N}, 79^{\circ} 34.995^{\prime} \mathrm{W}$, elevation $74 \mathrm{~m}$ ). The Colorado samples were collected from Chatfield Reservoir (ca. 600 ha, 39³3.464' N, $105^{\circ} 4.041^{\prime} \mathrm{W}$, elevation $1652 \mathrm{~m}$ ), a mesotrophic reservoir that supplies municipal water to the city of Denver, and the South Platte River $\left(39^{\circ} 31.244^{\prime} \mathrm{N}\right.$, $105^{\circ} 4.741^{\prime} \mathrm{W}$ ) approximately $800 \mathrm{~m}$ upstream from the reservoir.

Immediately following collection, samples were transported to the laboratory and filtered sequentially using $47 \mathrm{~mm}$ diameter GC50 glass fibre filters (Advantec MFS) and $47 \mathrm{~mm}$ diameter $0.45 \mu \mathrm{m}$ pore-size Durapore ${ }^{\circledR}$ membrane filters (Millipore). From each sample, $72 \mathrm{ml}$ of the filtrate was centrifuged in a SW40 Ti rotor (Beckman Coulter) at $25^{\circ} \mathrm{C}$ for $3 \mathrm{~h}$ at $182000 \times g$. Following centrifugation, the supernatant was decanted, $100 \mu \mathrm{l}$ of $10 \mathrm{mM}$ Tris $\cdot \mathrm{Cl}(\mathrm{pH}$ 8.0) were added to each centrifuge tube, and the pelleted material was soaked overnight at $4^{\circ} \mathrm{C}$, then vortexed for $30 \mathrm{~s}$, and resuspended using a pipettor. The resuspended material (ca. $600 \mu \mathrm{l}$ ) was transferred into screw-cap microcentrifuge tubes and stored at $-20^{\circ} \mathrm{C}$.

PCR, cloning and sequencing. Samples for PCR were subjected to a freeze-thaw treatment that consisted of heating at $95^{\circ} \mathrm{C}$ for 2 min and then freezing at $-20^{\circ} \mathrm{C}$ until the liquid was solid; this freeze-thaw treatment was repeated 3 times for each sample. Virus DNA polymerase genes were amplified from each sample in a single round of PCR in $50 \mu$ reaction volumes containing $2 \mu \mathrm{l}$ of the freeze-thaw treated sample, 20 and 30 pmol of the algal-virus-specific PCR primers AVS1 and AVS2 (Chen \& Suttle 1995), respectively, $1.5 \mathrm{mM} \mathrm{MgCl}_{2}, 0.2 \mathrm{mM}$ each dNTP, and $0.625 \mathrm{U}$ of Platinum ${ }^{\circledR}$ Taq DNA polymerase (Invitrogen) with the manufacturer-supplied reaction buffer. Negative control reactions were set up using $2 \mu \mathrm{l}$ of $\mathrm{H}_{2} \mathrm{O}$ substituted as template. Thermal cycling began with a denaturation step at $95^{\circ} \mathrm{C}$ for 2 min followed by 35 cycles of $95^{\circ} \mathrm{C}$ for $30 \mathrm{~s}, 50^{\circ} \mathrm{C}$ for $1 \mathrm{~min}$, and $72^{\circ} \mathrm{C}$ for $1 \mathrm{~min}$, followed by a final extension step at $72^{\circ} \mathrm{C}$ for 30 min in an MJ Research PTC-200 (Bio-Rad Laboratories), or an Applied Biosystems GeneAmp ${ }^{\circledR}$ PCR System 9700 thermal cycler. After thermal cycling, all $50 \mu \mathrm{l}$ of the reactions were loaded into $1.5 \% \mathrm{LE}$ agarose (Promega) gels, stained with $0.5 \mu \mathrm{g} \mathrm{ml}^{-1}$ ethidium bromide, and visualized using a Molecular Imager Gel Doc XR (Bio-Rad Laboratories) or an Epi Chemi II Darkroom (UVP, LLC) imaging system. In all cases, care was taken to ensure that the agarose gel was exposed to UV light for no more than $5 \mathrm{~s}$. Bands were 
then excised from the agarose gel and the DNA was extracted using a QIAquick Gel Extraction Kit (Qiagen) following the manufacturer's recommendations.

DNA fragments extracted from the gel bands were cloned using a pGEM-T Vector System II (Promega) according to the manufacturer's recommendations, except that $5 \mu \mathrm{l}$ of the ligation mixture was used to transform competent bacterial cells. To ensure that numerous colonies of transformed bacteria were available for sequencing, the entire volume of recovered, transformed bacteria (i.e. $1000 \mu$ l) was plated and incubated overnight at $37^{\circ} \mathrm{C}$. Bacterial colonies containing plasmids with insert DNA fragments were screened for appropriately sized inserts by PCR using the conditions described above, except that bacterial cells were used as templates for the reactions by transferring cells from the edge of a colony directly into the $\mathrm{PCR}$ reaction mixture. Following overnight incubation at $37^{\circ} \mathrm{C}$ in $5 \mathrm{ml}$ of LB broth with $100 \mu \mathrm{g} \mathrm{ml}^{-1}$ carbenicillin, plasmid DNA was purified from the screened colonies using a QIAprep Spin Miniprep Kit (Qiagen) and quantified using a NanoDrop ND-1000 spectrophotometer (NanoDrop Technologies) before being sent for automated sequencing. Samples from Colorado were sequenced at the CU Cancer Center DNA Sequencing \& Analysis Core in Aurora, CO, USA while samples from Ontario were sequenced at the McGill University and Genome Quebec Innovation Centre in Montréal, QC, Canada. Only full-length sequences (i.e. sequences that covered the entire $\sim 700$ base-pair DNA polymerase gene fragment) were used for further analysis, and sequences with ambiguous base-calls were excluded.

Analysis. All DNA and amino acid sequences were edited with BioEdit v.7.0.9 software (Hall 1999). Plasmid backbone sequences were deleted from the pol fragments obtained, pol fragments were aligned using ClustalW (Thompson et al. 1994), and sequence identity matrices were created for individual samples. For each sample, percent coverage (i.e. the expected probability that all species are represented in a sample) of the sequence library was calculated using $\mathrm{C}=1-$ $(\mathrm{N} / \mathrm{n})$, where $\mathrm{C}$ is the homologous coverage, $\mathrm{N}$ is the number of unique sequences in the sample (a unique sequences, or OTU, was defined as a DNA sequence that was not $>97 \%$ similar to any other sequence), and $\mathrm{n}$ is the total number of sequences in the sample (Good 1953, Singleton et al. 2001). Rarefaction analysis was conducted for each sample using Analytic Rarefaction v.1.3 (available at: www.uga.edu/strata/ software/Software.html), which uses the formulation described by Tipper (1979).

For phylogenetic analyses, amino acid sequences inferred from the DNA sequences of cloned PCR fragments were aligned to one another and to other virus sequences (see list below) using ClustalX (Thompson et al. 1997) with the Gonnet protein weight matrix (Gonnet et al. 1992) and an iteration step included for the final alignment. A preliminary alignment of DNA polymerase amino acids was created for all cultivated viruses (see list below) after intron sequences of the Chlorella-like algal viruses PBCV-1 and NY-2A and intein sequences in the Mimivirus (352 amino acids) and HaV01 (262 amino acids) were deleted (Zhang et al. 2001, Nagasaki et al. 2005). In addition, gaps that arose from amino acids found only in the outgroup NCLDVs (ASFV or Mimivirus) were removed from this alignment of cultivated viruses. For final alignment (after de-gapping all sequences and deleting the AVS1 and AVS2 primer regions) unique DNA sequences obtained were translated into amino acid sequences and aligned to all other sequences. Aligned amino acid sequences were analyzed by Bayesian inference of phylogeny using MrBayes 3.1.2 software (Ronquist \& Huelsenbeck 2003) with the following parameters: mixed models of evolution with fixed rate frequencies, $3 \times 10^{6}$ generations, 2 simultaneous runs of 4 chains, 0.25 burn-in fraction, and the analysis initiated from a random tree. Phylogenetic analysis was also conducted by neighbor-joining with 1000 bootstrap replicates (with Mega 4.0 software, Tamura et al. 2007) using the JTT protein substitution matrix (Jones et al. 1992). All phylogenetic trees were visualized and printed using Mega 4.0.

The virus family or source, abbreviations, and GenBank accession numbers of the pol sequences used in the phylogenetic analysis, but not obtained in this study included the outgroup NCLDVs Asfarviridae ASFV (X73330) and Mimivirus MimiV (AY653733, locus tag MIMI_R322), the Phycodnaviridae CbV-PW1 (U32983), CVA-1 (U32985), EhV-86 (AJ890364, locus tag EhV030), EsV-1 (AAK14511), FsV (AAB67116), HaV01 (AB194136), MpV-SG1 (U32981), MpV-SP1 (U32975), MpV-PB8 (U32980), NY-2A (M86837), OsV5 (NC_010191 locus tag OsV5_240f), PBCV-1 (M86836) and PgV-03T (AY345136), environmental sequences from the Gulf of Mexico OTU1 (U36931), OTU2 (U36932), OTU3 (U36933), OTU4 (U36934) and OTU5 (U36935), environmental sequences from the Southern Ocean SO98-1 (AF405572), SO98-2 (AF405573), SO983 (AF405574) and SO98-5 (AF405576), and environmental sequences from British Columbia (Canada) coastal waters BSA99-3 (AF405579), BSA99-6 (AF405582), BSB99-2 (AF405588), MIB99-1 (AF405591), MIB99-2 (AF405592), PSB99-1 (AF405593), PSC99-2 (AF405598), SIA99-1 (AF405590), JPavs-22 (AY145089), JPavs-37 (AY145090), JPavs-52 (AY145094), JPavs-55 (AY145096) and JPavs-64 (AY145097).

All sequences obtained in this study were deposited in GenBank. The 73 sequences from the water sample collected on September 18, 2007, in Lake Ontario were 
assigned accession numbers EU336573-EU336645; the 62 sequences from the water sample collected on October 10, 2007 in Lake Ontario were assigned accession numbers EU336646-EU336707; the 44 sequences from the water sample collected on October 4, 2007, in Crawford Lake were assigned accession numbers EU336433-EU336476; the 25 sequences from the water sample collected on June 20, 2005, in Chatfield Reservoir were assigned accession numbers EU336477-EU336501; the 71 sequences from the water sample collected on July 12, 2005, in Chatfield Reservoir were assigned accession numbers EU336502-EU336572; the 46 sequences from the water sample collected on June 20, 2005, in the South Platte River were assigned accession numbers EU336708-EU336753; and the 50 sequences from the water sample collected on July 12, 2005, in the South Platte River were assigned accession numbers EU336754-EU336803.

\section{RESULTS}

Electrophoresis of PCR products revealed that every reaction produced a single amplified DNA fragment of approximately 700 base-pairs (data not shown). Furthermore, for every sample cloning the PCR products produced at least 100 colonies of bacteria containing a plasmid with an appropriately sized insert DNA fragment (as indicated by blue-white screening and PCR). Thus, the PCR amplification and cloning methods provided ample material for sequence analyses and species richness determinations.

Initially, 25 colonies containing plasmids with cloned PCR fragments were randomly selected for each sample and the insert DNA fragments in the purified plasmids were sequenced. Percent coverage values of the resulting sequence library were calculated for each sample. Additional colonies were then randomly selected and sequenced until the homologous coverage value for each sample exceeded $85 \%$. The results of the sequencing effort for each sample are summarized in Table 1. Although one sample (CRa, Table 1) exceeded $85 \%$ coverage after sequencing only 25 clones, in all other cases it was necessary to sequence a larger number of colonies to exceed $85 \%$ coverage. For example, sequencing 73 clones from sample LO1a resulted in a clone library with a coverage value of $89 \%$. Although these coverage values represent crude estimates of the total species richness in a sample, the trends observed from

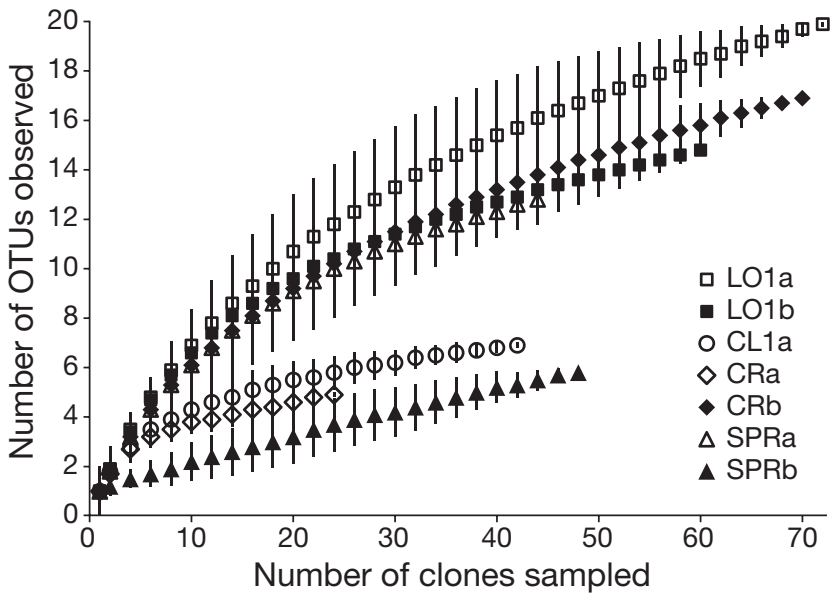

Fig. 1. Rarefaction analysis of clone libraries sequenced from each sample location. A key to sample abbreviations is given in Table 1. Error bars show variances (Var) of the expected numbers of species

percentage coverage calculations (i.e. of samples with greater richness) were reinforced by rarefaction analysis.

Rarefaction analysis of the clone libraries from each sample showed that Lake Ontario samples LO1a and LO1b, Chatfield Reservoir sample CRb, and South Platte River sample SPRa were richer in virus OTUs than Chatfield Reservoir sample CRa, South Platte River sample SPRb and Crawford Lake sample CL1a (Fig. 1). For example, when each sample was rarefied to 24 randomly selected clones, the expected numbers of OTUs for samples LO1a, LO1b, CRb, and SPRa were $11.8,10.4,10.2$, and 10, respectively, while the expected numbers of OTUs for samples CL1a, CRa, and $\mathrm{SPRb}$ were only 5.8, 4.9, and 3.7, respectively. Although rarefaction analysis showed that samples LO1a, LO1b, CRb, and SPRa were the richest in OTUs, the variances for estimates of the observed number of OTUs for these samples overlapped through most of the rarefaction curve (Fig. 1). Nonetheless, rarefaction curves of samples CL1a, CRa, and SPRb (with lower numbers of expected OTUs) were clearly distinguishable from the group with greater richness (Fig. 1).
Table. 1. Sample abbreviations, locations, dates, and clone library information

\begin{tabular}{|llcccc|}
\hline $\begin{array}{l}\text { Sample } \\
\text { name }\end{array}$ & Location & $\begin{array}{c}\text { Date } \\
\text { (dd/mm/yy) }\end{array}$ & $\begin{array}{c}\text { No. of clones } \\
\text { sequenced }\end{array}$ & $\begin{array}{c}\text { No. of } \\
\text { unique OTUs }\end{array}$ & $\begin{array}{c}\text { Sequencing } \\
\text { coverage (\%) }\end{array}$ \\
\hline LO1a & Lake Ontario & $18 / 09 / 07$ & 73 & 20 & 89.0 \\
LO1b & Lake Ontario & $10 / 10 / 07$ & 62 & 15 & 90.3 \\
CL1a & Crawford Lake & $04 / 10 / 07$ & 44 & 7 & 95.5 \\
CRa & Chatfield Reservoir & $20 / 06 / 05$ & 25 & 5 & 96.0 \\
CRb & Chatfield Reservoir & $12 / 07 / 05$ & 71 & 17 & 90.1 \\
SPRa & South Platte River & $20 / 06 / 05$ & 46 & 13 & 92.0 \\
SPRb & South Platte River & $12 / 07 / 05$ & 50 & 6 & 89.1 \\
\hline
\end{tabular}


Phylogenetic analyses conducted with Bayesian Inference and Neighbor-joining analyses demonstrated that the unique DNA polymerase sequences obtained clustered among cultivated algal viruses rather than with DNA polymerase sequences from the outgroups NCLDVs ASFV and MimiV (Fig. 2). Overall, most of the sequences from freshwater environments tended to cluster together rather than among sequences from marine environments, and sequences from Colorado and Ontario tended to form separate clusters. For example, 38 of the 41 unique sequences from Colorado clustered together to form the group labelled 'Freshwater II' (Fig. 2). Similarly, the Ontario sequences also tended to cluster together, either within the 'Freshwater I' group of freshwater sequences, or within the 'Freshwater and marine' group of sequences (Fig. 2). However, there were exceptions to these generalizations. For example, Colorado sequence CRb-04 was located among sequences from cultivated marine algal viruses and marine environmental clones in the Freshwater and marine group; Colorado sequences CRb-09, and CRb-29 clustered among Ontario sequences in the Freshwater I group, and Ontario sequence LO1a-49 was not closely related any other freshwater sequence, but was most closely related to the marine sequence BSB99-2 from British Columbia coastal waters. It is also notable that none of the freshwater sequences obtained in this study clustered among the only cultivated phycodnaviruses from freshwater environments (Chloroviruses CVA-1, PBCV-1, and NY-2A).

\section{DISCUSSION}

Diverse gene sequences closely related to cultivated phycodnavirus DNA polymerase sequences were recovered from a variety of freshwater environments. Individual locations sampled at different dates, and different locations sampled on the same date varied in sequence richness. Furthermore, freshwater environments contain gene sequences that were more closely related to DNA polymerase sequences from cultivated marine phycodnaviruses than sequences from cultivated freshwater phycodnaviruses belonging to the genus Chlorovirus. Although several studies of conserved phage structural genes have clearly demonstrated that molecular approaches can be used to infer the community richness of viruses that infect freshwater algae (e.g. Wang \& Chen 2004, Short \& Suttle 2005, Wilhelm et al. 2006), ours is the first report of genetic richness of freshwater viruses that infect eukaryotic algae.

Without exception, the DNA polymerase sequences obtained in this study were more closely related to phycodnavirus DNA polymerases than DNA polymerases of the outgroups NCLDVs ASFV and MimiV. In fact, all of the sequences clustered between sequences from cultivated phycodnaviruses belonging to the virus genera Prasinovirus and Chlorovirus. Given that several independent lines of research on $\delta$-DNA polymerases (Chen et al. 1996, Villarreal \& DeFilippis 2000) and on multiple genes from a variety of NCLDVs (Iyer et al. 2001, Allen et al. 2006, Iyer et al. 2006) support the hypothesis that the Phycodnaviridae is a monophyletic group within the NCLDVs, there is little doubt that the virus sequences we obtained originated from phycodnaviruses. Because the gene fragments sequenced in this study were obtained by amplification with algal-virus-specific PCR primers, recovery of phycodnavirus sequences was the expected result. Nonetheless, this is the first study demonstrating the presence of freshwater phycodnavirus sequences that are closely related to marine phycodnavirus sequences, and it suggests that phycodnaviruses may infect a variety of freshwater eukaryotic algae.

As a strategy to maximize the recovery of unique OTUs while simultaneously minimizing our sequencing efforts, clones from each sample were sequenced in small batches until the calculated homologous coverage exceeded an arbitrary value of $85 \%$. As noted in 'Materials and methods', we used a 97\% DNA sequence identity to define an OTU. Although somewhat arbitrary, 97\% identity (1) minimizes the possibility that unique sequences arose due to PCR or sequencing errors, (2) is fairly conservative, and (3) follows the example of other studies of molecular diversity (e.g. McCaig et al. 1999, Hughes et al. 2001, Singleton et al. 2001). The strategy of sequencing until at least $85 \%$ homologous coverage was obtained did not guarantee all unique OTUs were recovered from a clone library, yet we speculated that the most abundant OTUs in our library would be recovered at this coverage. Because the slope of the rarefaction curves (except for SPRb) decreased with increasing numbers of clones sampled (Fig. 1), it is probable that the most abundant OTUs in each clone library were represented. However, since none of the rarefaction curves reached an asymptote, it is unlikely that all unique sequences were obtained from any sample. Even though the cost and effort of recovering the rarest members of these communities was prohibitive and beyond the scope of this study, the addition of 371 environmental phycodnavirus DNA polymerase sequences that we obtained is a significant contribution to GenBank relative to the 45 previously available environmental phycodnavirus DNA polymerase sequences.

It is very likely that unique virus sequences were missed in this study. Nonetheless, some interesting 
Fig. 2. Consensus tree from Bayesian inference of the phylogenetic relationships of amino acid sequences inferred from cultivated and environmental virus DNA polymerase gene sequences. A key to sample abbreviations is given in Table 1; each sample abbreviation code is followed by an arbitrary clone number. Values at the nodes indicate clade credibility (as percent probability) and, where tree topology was perfectly conserved, second values indicate percent bootstrap values from a neighbour-joining tree of 1000 bootstrap replicates (when the bootstrap value was $>90 \%$, the second value is given as ${ }^{*}$ ). The scale bar value shows the proportion of expected changes per site

Sample key

Cultivated viruses

Marine PCR

Lake Ontario PCR

Crawford Lake PCR

Chatfield Reservoir PCR

South Platte River PCR

\section{Outgroup taxa}

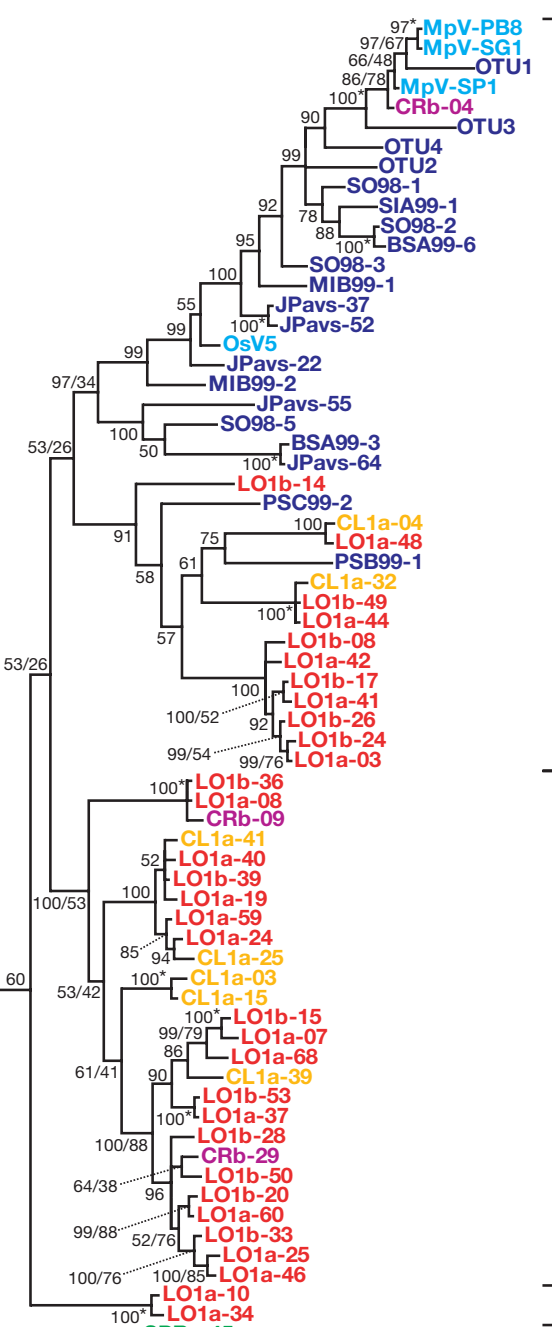

Freshwater and marine

Freshwater I

Freshwater II

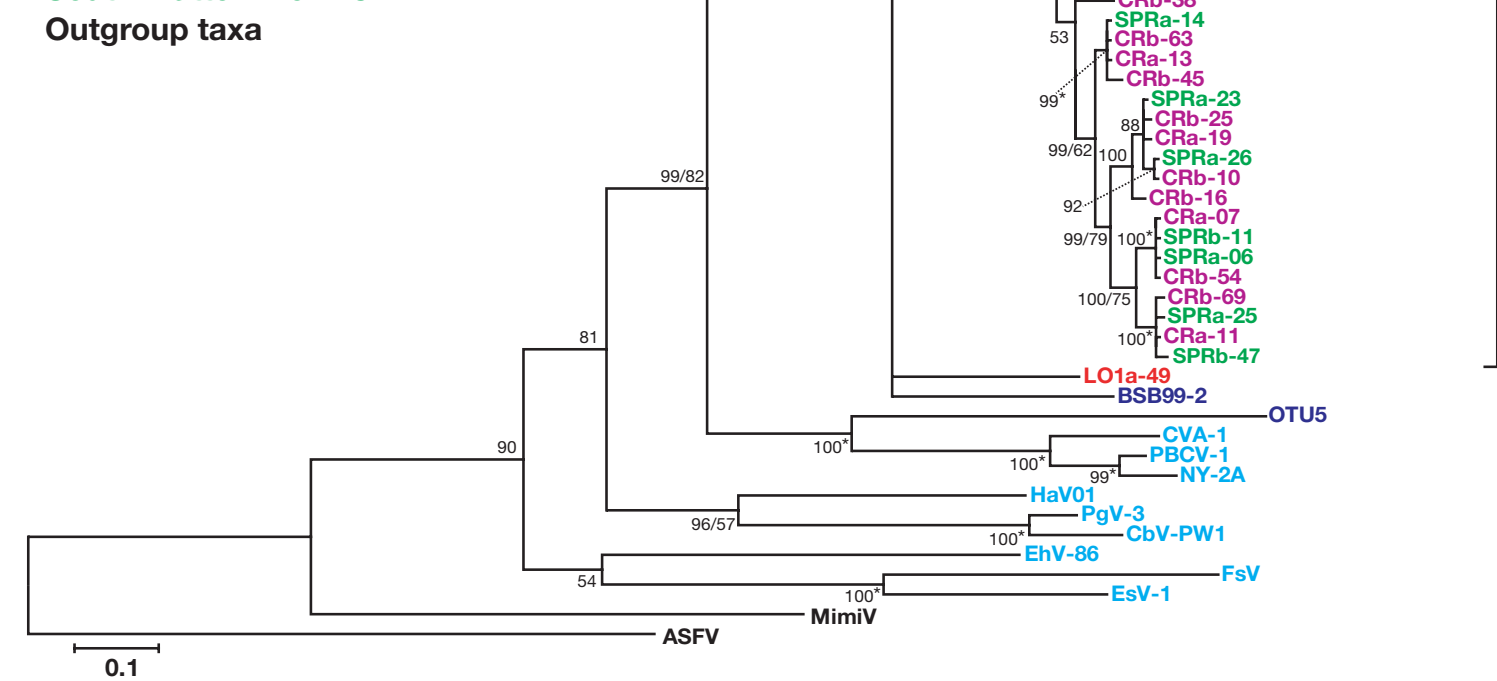


richness trends were observed. For instance, virus richness was variable in space and time. Although Crawford Lake contained fewer virus OTUs than the nearby but much larger Lake Ontario, the sample taken in July 2005 from the much smaller Chatfield Reservoir was as rich in unique virus sequences as Lake Ontario. Although the OTU richnesses of the 2 clone libraries constructed from Lake Ontario PCR products were very similar, the clone libraries from the South Platte River and the Chatfield Reservoir varied by sample date. The South Platte River sample collected in July contained fewer OTUs than the sample collected in June. The reverse pattern occurred in Chatfield Reservoir clone libraries; this may be related to the location of the South Platte River sampling site upstream from Chatfield Reservoir. The South Platte River watershed may be the ultimate source of Chatfield Reservoir's microbial inocula. However, these relationships are largely speculative and limited by a sampling design that was not intended to account for temporal variability. Our objective was a first survey of phycodnavirus diversity in freshwater environments. Although the rarefaction curves did not reach asymptotes, visual inspection suggests that the Phycodnaviridae richness in the samples was in the 10s of OTUs, rather than in the 100 s or 1000 s. This crude estimate of total richness is corroborated by calculations with other species richness estimators. For example, using the nonparametric richness estimator Chao1 (Hughes et al. 2001), the total richnesses of samples LO1a and CRb were 28.00 and 25.17 OTUs, respectively. It is important to note that the PCR methods used (amplification with primers AVS1 and AVS2) cannot recover all algal virus DNA polymerase genes; for example, the Coccolithovirus EhV-86 DNA polymerase gene cannot be amplified with these primers. Furthermore, RNA viruses that infect phytoplankton have been isolated (Tai et al. 2003). Therefore, although the PCR primers AVS1 and AVS2 have been used previously to amplify diverse phycodnaviruses (Chen et al. 1996, Short \& Suttle 2002, 2003), our estimates of the richness of freshwater viruses that infect algae are conservative.

For the sake of simplicity and clarity, only the Bayesian consensus tree is presented. However, the overall topology of the neighbor-joining consensus phylogram was very similar to that of the Bayesian phylogram, and the 2 phylogenies contained many identical bifurcations. Importantly, the major nodes between the large clusters of sequences - Freshwater and marine, Freshwater I, and Freshwater II-were identical (Fig. 2). Although the presence of large freshwater groups in the phylogenies suggests that many of the freshwater virus sequences are genetically distinct from marine virus sequences, this interpretation is likely erroneous as the support values at some of the major bifurcations are rather low. The bifur- cation that splits the Freshwater and marine and Freshwater I groups from the Freshwater II group has a probability of only $53 \%$ and a bootstrap value of only $36 \%$ (Fig. 2). Similarly, the bifurcation that splits the Freshwater and marine group from the Freshwater I group is supported at a probability of $53 \%$ and a bootstrap value of $26 \%$ (Fig. 2). Thus, the nodes that separate the freshwater sequences from marine sequences may not reflect true evolutionary relationships of these sequences. Further, the appearance of the phylogenetic tree presented in Fig. 2 is heavily biased by the large number of sequences we obtained. On the other hand, the fact that some of the freshwater phycodnavirus gene fragments obtained in this study (e.g. sequences within the Freshwater and marine group, Fig. 2) are closely related to marine phycodnavirus sequences corroborates results from studies of cultivated viruses. For example, Dunigan et al. (2006) suggest that PBCV-1 capsid protein is most closely related to environmental sequences from the Sargasso Sea, although PBCV-1 is a freshwater virus.

Many sequences from the same region (i.e. Colorado, USA versus Ontario, Canada) clustered together suggesting that the viruses (and possibly their hosts) from geographically separated locations are genetically distinct. However, there are exceptions to this generalization, and some sequences from each region were most closely related to sequences obtained from geographically distant locations (e.g. Lake Ontario sequence LO1a-49 was closely related to sequence BSB99-2 from British Columbia coastal waters, and the Chatfield Reservoir sequence CRb-04 clustered among sequences OTU1 and OTU3 from the Gulf of Mexico and the sequence from cultivated viruses that infect the marine alga Micromonas pusilla). Further, it is unclear from the DNA polymerase sequences of cultivated viruses how genetic distance might be used to define different virus genera; the genetic distance between DNA polymerase fragments of Phaeoviruses EsV-1 and FsV is greater than the distance between the most distant sequences in the Freshwater II group (SPRb-33 and SPRa-45); moreover, the distance between SPRa-31 and SPRa-45 exceeds that between Prymnesioviruses CbV-PW1 and PgV-03T, and between Prasinoviruses MpV-SG1 and MpV-SP1. Clearly it is necessary to cultivate and sequence more phycodnaviruses before molecular data can be used to classify unknown Phycodnaviridae by their evolutionary relationships, or more importantly, by the hosts they infect.

We have demonstrated that freshwater environments are home to diverse Phycodnaviruses. Although the PCR approach used can recover only a poorlydefined subset of phycodnavirus DNA polymerase genes, we provide further evidence that relatively few algal viruses have been cultivated in comparison with 
the richness of viruses that can be observed using molecular techniques. A surprising result was that no pol sequences closely related to the cultivated freshwater Chloroviruses PBCV-1, NY-2A, and CVA1 were recovered from the clone libraries we created. Given that Chlorella is a common freshwater phytoplankton and that the PCR primers AVS1 and AVS2 have been used previously to amplify pol fragments from viruses that infect symbiotic Chlorella-like algae (Chen \& Suttle 1996, Short \& Suttle 1999), further discussion of this surprising result is called for. It is possible that, when the samples were collected, Chloroviruses with DNA polymerase genes amplifiable by AVS1 and AVS2 were not present, or were below detectable abundance limits; it is also possible that the AVS1 and AVS2 primers preferentially amplified other pol sequences, swamping any Chlorovirus targets that were present during the PCR reactions or cloning steps. Another possibility is that Chloroviruses were present in the samples, but the taxa were not homologous within regions targeted by AVS1 and AVS2. Future studies involving more frequent sample collection, examination of phytoplankton richness and new PCR primer sets designed to target phycodnavirus pol sequences missed by AVS1 and AVS2 will help resolve these possibilities. Furthermore, additional, complementary primer sets that target other phycodnavirus genes (or other regions of the phycodnavirus pol) will be necessary to obtain a comprehensive picture of phycodnavirus diversity. Finally, the phycodnavirus sequence diversity in a variety of North American freshwater environments demonstrates that these environments are promising locations for future studies of these ecologically and evolutionarily interesting entities.

Acknowledgements. We thank the Colorado Department of Natural Resources for allowing us to collect samples from Chatfield Reservoir and South Platte River in Chatfield State Park. Similarly, we thank Conservation Halton for permitting us to collect samples from Crawford Lake. We thank K. Hall, D. Hathorn and R. Kysela for assistance collecting samples from Colorado, and S.M. Holland for providing the freely available software Analytic Rarefaction v.1.3. This project was made possible through funding to S.M.S. from the University of Denver, and the University of Toronto Mississauga.

\section{LITERATURE CITED}

Allen MJ, Schroeder DC, Holden MTG, Wilson WH (2006) Evolutionary history of the Coccolithoviridae. Mol Biol Evol 23:86-92

Allen MJ, Martinez-Martinez J, Schroeder DC, Somerfield PJ, Wilson WH (2007) Use of microarrays to assess viral diversity: from genotype to phenotype. Environ Microbiol 9:971-982

Bergh O, Borsheim KY, Bratbak G, Heldal M (1989) High abundance of viruses found in aquatic environments. Nature 340:467-468
Brussaard CPD (2004) Viral control of phytoplankton populations - a review. J Eukaryot Microbiol 51:125-138

Chen F, Suttle CA (1995) Amplification of DNA-polymerase gene fragments from viruses infecting microalgae. Appl Environ Microbiol 61:1274-1278

Chen F, Suttle CA (1996) Evolutionary relationships among large double-stranded DNA viruses that infect microalgae and other organisms as inferred from DNA polymerase genes. Virology 219:170-178

Chen F, Suttle CA, Short SM (1996) Genetic diversity in marine algal virus communities as revealed by sequence analysis of DNA polymerase genes. Appl Environ Microbiol 62:2869-2874

Cottrell MT, Suttle CA (1991) Wide-spread occurrence and clonal variation in viruses which cause lysis of a cosmopolitan, eukaryotic marine phytoplankter, Micromonas-pusilla. Mar Ecol Prog Ser 78:1-9

Dunigan DD, Fitzgerald LA, Van Etten JL (2006) Phycodnaviruses: a peek at genetic diversity. Virus Res 117: $119-132$

Farnell-Jackson EA, Ward AK (2003) Seasonal patterns of viruses, bacteria and dissolved organic carbon in a riverine wetland. Freshw Biol 48:841-851

Fischer UR, Velimirov B (2002) High control of bacterial production by viruses in a eutrophic oxbow lake. Aquat Microb Ecol 27:1-12

Fuhrman JA (1999) Marine viruses and their biogeochemical and ecological effects. Nature 399:541-548

Gonnet GH, Cohen MA, Benner SA (1992) Exhaustive matching of the entire protein-sequence database. Science 256:1443-1445

Good IJ (1953) The population frequencies of species and the estimation of population parameters. Biometrika 40: $237-264$

Hall TA (1999) BioEdit: a user-friendly biological sequence alignment editor and analysis program for Windows 95/98/NT. Nucleic Acids Symp Ser 41:95-98

Hennes KP, Simon M (1995) Significance of bacteriophages for controlling bacterioplankton growth in a mesotrophic lake. Appl Environ Microbiol 61:333-340

$>$ Hughes JB, Hellmann JJ, Ricketts TH, Bohannan BJM (2001) Counting the uncountable: statistical approaches to estimating microbial diversity. Appl Environ Microbiol 67: 4399-4406

Iyer LM, Aravind L, Koonin EV (2001) Common origin of four diverse families of large eukaryotic DNA viruses. J Virol 75:11720-11734

Iyer LM, Balaji S, Koonin EV, Aravind L (2006) Evolutionary genomics of nucleo-cytoplasmic large DNA viruses. Virus Res 117:156-184

Jacquet S, Domaizon I, Personnic S, Ram ASP, Hedal M, Duhamal S, Sime-Ngando T (2005) Estimates of protozoan- and viral-mediated mortality of bacterioplankton in Lake Bourget (France). Freshw Biol 50:627-645

Jiang S, Steward G, Jellison R, Chu W, Choi S (2004) Abundance, distribution, and diversity of viruses in alkaline, hypersaline Mono Lake, California. Microb Ecol 47:9-17

Jones DT, Taylor WR, Thornton JM (1992) The rapid generation of mutation data matrices from protein sequences. Comput Appl Biosci 8:275-282

Klut ME, Stockner JG (1990) Virus-like particles in an ultraoligotrophic lake on Vancouver Island, British-Columbia. Can J Fish Aquat Sci 47:725-730

Laybourn-Parry J, Hofer JS, Sommaruga R (2001) Viruses in the plankton of freshwater and saline Antarctic lakes. Freshw Biol 46:1279-1287 
Maranger R, Bird DF (1995) Viral abundance in aquatic systems: a comparison between marine and fresh waters. Mar Ecol Prog Ser 121:217-226

Martinez JM, Schroeder DC, Larsen A, Bratbak G, Wilson WH (2007) Molecular dynamics of Emiliania huxleyi and cooccurring viruses during two separate mesocosm studies. Appl Environ Microbiol 73:554-562

Mayer JA, Taylor FJR (1979) A virus which lyses the marine nanoflagellate Micromonas pusilla. Nature 281:299-301

McCaig AE, Glover LA, Prosser JI (1999) Molecular analysis of bacterial community structure and diversity in unimproved and improved upland grass pastures. Appl Environ Microbiol 65:1721-1730

Nagasaki K, Shirai Y, Tomaru Y, Nishida K, Pietrokovski S (2005) Algal viruses with distinct intraspecies host specificities include identical intein elements. Appl Environ Microbiol 71:3599-3607

Proctor LM, Fuhrman JA (1990) Viral mortality of marine bacteria and cyanobacteria. Nature 343:60-62

Ronquist F, Huelsenbeck JP (2003) MrBayes 3: Bayesian phylogenetic inference under mixed models. Bioinformatics 19:1572

Safferman RS, Morris ME (1963) Algal virus-isolation. Science 140:679-680

Short CM, Suttle CA (2005) Nearly identical bacteriophage structural gene sequences are widely distributed in both marine and freshwater environments. Appl Environ Microbiol 71:480-486

Short SM, Suttle CA (1999) Use of the polymerase chain reaction and denaturing gradient gel electrophoresis to study diversity in natural virus communities. Hydrobiologia 401:19-32

Short SM, Suttle CA (2002) Sequence analysis of marine virus communities reveals that groups of related algal viruses are widely distributed in nature. Appl Environ Microbiol 68:1290-1296

Short SM, Suttle CA (2003) Temporal dynamics of natural communities of marine algal viruses and eukaryotes. Aquat Microb Ecol 32:107-119

Singleton DR, Furlong MA, Rathbun SL, Whitman WB (2001) Quantitative comparisons of 16S rRNA gene sequence libraries from environmental samples. Appl Environ Microbiol 67:4374-4376

Suttle CA (2005) Viruses in the sea. Nature 437:356-361

Tai V, Lawrence JE, Lang AS, Chan AM, Culley AI, Suttle CA (2003) Characterization of HaRNAV, a single-stranded RNA virus causing lysis of Heterosigma akashiwo (Raphidophyceae). J Phycol 39:343-352

Tamura K, Dudley J, Nei M, Kumar S (2007) MEGA4: molecular evolutionary genetics analysis (MEGA) software version 4.0. Mol Biol Evol 24:1596-1599

Editorial responsibility: Gunnar Bratbak, Bergen, Norway
Thompson JD, Higgins DG, Gibson TJ (1994) Clustal W: improving the sensitivity of progressive multiple sequence alignment through sequence weighting, position-specific gap penalties and weight matrix choice. Nucleic Acids Res 22:4673-4680

Thompson JD, Gibson TJ, Plewniak F, Jeanmougin F, Higgins DG (1997) The ClustalX windows interface: flexible strategies for multiple sequence alignment aided by quality analysis tools. Nucleic Acids Res 25:4876-4882

Tipper JC (1979) Rarefaction and rarefiction - use and abuse of a method in paleoecology. Paleobiology 5:423-434

Torrella F, Morita RY (1979) Evidence by electron micrographs for a high incidence of bacteriophage particles in the waters of Yaquina Bay, Oregon: ecological and taxonomic implications. Appl Environ Microbiol 37: 774-778

van Etten JL, Meints RH, Kuczmarski D, Burbank DE, Lee K (1982) Viruses of symbiotic Chlorella-like algae isolated from Paramecium bursaria and Hydra viridis. Proc Natl Acad Sci USA 79:3867-3871

Villarreal LP, DeFilippis VR (2000) A hypothesis for DNA viruses as the origin of eukaryotic replication proteins. J Virol 74:7079-7084

Vrede K, Stensdotter U, Lindstrom ES (2003) Viral and bacterioplankton dynamics in two lakes with different humic contents. Microb Ecol 46:406-415

Wang K, Chen F (2004) Genetic diversity and population dynamics of cyanophage communities in the Chesapeake Bay. Aquat Microb Ecol 34:105-116

Weinbauer MG, Christaki U, Nedoma J, Šimek K (2003) Comparing the effects of resource enrichment and grazing on viral production in a meso-eutrophic reservoir. Aquat Microb Ecol 31:137-144

Wilhelm SW, Smith REH (2000) Bacterial carbon production in Lake Erie is influenced by viruses and solar radiation. Can J Fish Aquat Sci 57:317-326

- Wilhelm SW, Suttle CA (1999) Viruses and nutrient cycles in the sea. BioScience 49:781-788

Wilhelm SW, Carberry MJ, Eldridge ML, Poorvin L, Saxton MA, Doblin MA (2006) Marine and freshwater cyanophages in a Laurentian Great Lake: evidence from infectivity assays and molecular analyses of g20 genes. Appl Environ Microbiol 72:4957-4963

> Wommack KE, Colwell RR (2000) Virioplankton: viruses in aquatic ecosystems. Microbiol Mol Biol Rev 64:69-114

Zhang Y, Adams B, Sun L, Burbank DE, Van Etten JL (2001) Intron conservation in the DNA polymerase gene encoded by Chlorella viruses. Virology 285:313-321

Zingone A, Sarno D, Forlani G (1999) Seasonal dynamics in the abundance of Micromonas pusilla (Prasinophyceae) and its viruses in the Gulf of Naples (Mediterranean Sea). J Plankton Res 21:2143-2159

Submitted: December 17, 2007; Accepted: February 13, 2008 Proofs received from author(s): April 14, 2008 